\title{
Epistemology, socialization, help seeking, and gender-based views in in-person and online, hands-on undergraduate physics laboratories
}

\author{
Drew J. Rosen® \\ Stony Brook University, Institute for STEM Education, Stony Brook, New York 11794-5233, USA \\ Angela M. Kelly๑* \\ Stony Brook University, Department of Physics and Astronomy and Institute for STEM Education, \\ Stony Brook, New York 11794-5233, USA
}

(Received 23 February 2020; accepted 15 July 2020; published 28 August 2020)

\begin{abstract}
Undergraduate physics laboratory course structures have been identified in policy reports for novel design innovations to meet the needs of a diverse and growing student population. To this end, an online, hands-on laboratory option was implemented at a large, public university for introductory physics students using the iOLab device. To determine whether students in this new course structure had similar perspectives to their in-person counterparts in terms of select attitudinal measures, a quasiexperimental, observational quantitative study was undertaken to measure students' epistemological views as well as their beliefs about socialization and help seeking in online and in-person laboratory environments. Undergraduate students who were enrolled in calculus-based introductory physics $(N=998)$ were surveyed in the second half of the semester to elicit their epistemological beliefs about physics laboratory work and their views on social engagement and academic help seeking in the laboratory. Parametric and nonparametric comparisons of central tendency were employed to measure differences between students in the in-person and online laboratories, as well as gender differences and associated interaction effects. Students showed no overall differences in attitudes related to epistemological and help seeking beliefs. There were significant differences related to views of socialization; students taking in-person physics laboratories valued socialization more than students taking the course online. Gender differences in epistemological and help seeking beliefs were identified overall, however, these differences were no longer significant when examining the interactions of laboratory type and gender. This finding suggests that self-selection into laboratory type may diminish gender gaps in affective domains by allowing students to choose the laboratory structure that meets their learning and logistical needs. In terms of physics epistemology, socialization and help seeking in the laboratory may not be as important to students' perceptions of physics knowledge acquisition as previously thought. This study provides insights into the feasibility of online, hands-on laboratory experiences to meet the affective goals articulated in in-person laboratories, as well as institutional recommendations for advising students to select courses that match their individual learning styles.
\end{abstract}

DOI: 10.1103/PhysRevPhysEducRes.16.020116

\section{INTRODUCTION}

The call for improvement in undergraduate science education has been emphasized by numerous policy reports in recent years [1-3]. Suggested reforms included improving introductory coursework, creating a communal atmosphere of science, technology, engineering, and mathematics (STEM) learners, and adapting a diversification of teaching

*angela.kelly@stonybrook.edu

Published by the American Physical Society under the terms of the Creative Commons Attribution 4.0 International license. Further distribution of this work must maintain attribution to the author(s) and the published article's title, journal citation, and DOI. methods [4]. The National Research Council released a report on the status of undergraduate physics education, Adapting to a Changing World: Challenges and Opportunities in Undergraduate Physics Education, which recommended modifying courses to meet the needs of a diverse student body, particularly those who have been traditionally underrepresented in the field [5]. Changes in physics laboratory courses have been driven by the need to prepare students for 21 st century careers [6,7] and to engage students in authentic scientific practices such as thinking and acting like a physicist [7-9]. Such instructional improvements should be supported by empirically based evidence, which might include research on the affective domain, including factors such as student attitudes, perceptions, and values [5]. 
Universities with expanding STEM student populations are often faced with a need for larger and higher quality physics laboratory offerings with pressures of limited financial resources and over capacity classrooms [5]. Laboratory courses tend to be resource intensive forms of instruction requiring significant investments in instructor time, specialized equipment, and physical laboratory space [10]. Novel course structures such as online physics laboratory instruction may provide low cost solutions to many of these issues [11].

Students' epistemological beliefs about the construction of knowledge in a physics laboratory class are often based upon their expectations [12], classroom experiences [12,13], and their measures of success [14]. Communication with fellow students and instructors may contribute to their beliefs about physics learning. In an in-person laboratory course, socialization and help seeking strategies undertaken by students are often facilitated by students' close, physical proximity to fellow students and teaching assistants. These facile forms of communication are not necessarily available to students taking an equivalent online class. Social variables including peer interactions, the social atmosphere in the classroom, and the degree of support from instructors have been shown to influence science learning and student retention in STEM fields [15-19].

Using a quasiexperimental, observational design, this study focused on the following research questions: (i) What are undergraduate students' beliefs regarding the epistemological value of laboratory tasks, socialization, and help seeking in the physics laboratory? (ii) What are the similarities and differences between these epistemological, socialization, and help seeking beliefs when comparing students taking an in-person laboratory course, and those individuals working alone in an online, hands-on laboratory course? (iii) How do women and men perceive epistemological views, socialization, and help seeking in different physics laboratory environments?

\section{LITERATURE REVIEW}

\section{A. Purpose of laboratory work}

The laboratory has been valued by both scientists and science educators as a critical part of learning science $[7,20,21]$. Physics by nature is fundamentally an experimental science, which is why the laboratory is such an essential component of a physics student's undergraduate experience. Students who engage in scientific laboratory work may benefit by developing scientific habits preparing them to be global citizens in the 21 st century natural world $[6,7]$.

Laboratory work has been a cornerstone of physics curricula for over a century $[20,22]$. During this time, there has been evolution in the purpose of laboratory work, the selection of investigations, and how experiments have been conducted [20,23]. With an increased call for improvement in undergraduate physics laboratories, the
American Association of Physics Teachers (AAPT) made recommendations based on six focus areas: (1) constructing physics knowledge, (2) modeling, (3) designing physics experiments, (4) developing technical and practical laboratory skills, (5) analyzing and visualizing data, and (6) communicating physics. Thinking like a physicist and constructing knowledge permeate all of the goals articulated by AAPT in their laboratory guidelines document [7].

Laboratory work provides an opportunity for students to engage in scientific inquiry directly, and to gain new insights while performing experiments [24]. This may include participating in argumentation $[25,26]$ and establishing causal mechanisms for physical phenomena $[27,28]$. Physics laboratory experiences can relate physics and scientific skills to other coursework as well as everyday life [13,29]. This type of engagement may enhance a student's attention, effort, and conceptual learning [30].

\section{B. Collaborative learning}

Collaboration has often been considered a vital part of learning [31,32]. This is particularly true in the sciences, which are typically not practiced alone but as part of a community of researchers who engage in discourse and learn from one another [33]. Curriculum and pedagogy in science classrooms, specifically with regard to laboratory work, should strive to provide students with authentic scientific experiences that involve collaborative learning [8,34]. Research has suggested that working in groups allows students to negotiate understandings and build consensus through discursive practices [13,35]. Students improve metacognition by performing investigations and defending their ideas with one another [7]. Socially mediated metacognition may guide the troubleshooting process when laboratory groups determine the best feasible strategy to move forward [36]. However, social interaction and collaboration do not necessarily have to occur in the same physical laboratory space [37].

Many researchers have explored gender-based disparities in attitudes, performance, and retention in undergraduate physics $[19,38,39]$. These disparities are worthy of consideration when investigating how students' beliefs about physics learning are related to social and cognitive factors. These factors, which research has shown are often differentiated for men and women [39], may vary depending upon the nature and extent of socialization and collaboration in laboratory classes. Women have often shown stronger preferences than men for small group discussion, social negotiation, and interactive engagement in the physics classroom $[40,41]$. However, there has been little research on whether these preferences may be observed in online laboratory environments.

\section{Distance learning and online lab work}

The internet has catalyzed a revolution in distance learning. As of 2016, roughly $43 \%$ of undergraduate 
students were enrolled in at least one online course (up from $32 \%$ in 2012) and nearly $11 \%$ completed their entire degree programs online (up from 6.5\%) [42]. The majority of students enrolled in distance courses (52.8\%) were also taking a class on campus, indicating the convenience and appeal of online courses even for undergraduates taking inperson classes [43].

The ubiquity of the internet came with innovations in the way science laboratories are conducted. Rather than having to go to a special room with specialized equipment at a specific time, students may conduct entire scientific experiments asynchronously from any location. Having laboratory work structured in this manner may also provide smoother integration between concepts covered in lecture and how they are applied in laboratory work, since there is often more flexibility in when laboratory experiments may be completed [44]. Online laboratory instruction provides opportunities and accessibility to students who may not otherwise be able to take in-person laboratory courses because they are part-time students, in a caring role, or have disabilities that might prevent them from having an equivalent laboratory experience [45,46]. Online labs may alleviate the problems associated with costly equipment, instruction, and space that would prevent resource constrained departments from increasing their laboratory enrollments [47].

The internet also allows for videos to be shared easily, which may be used to supplement laboratory manuals or lecture information. Videos of demonstrations have been shown to be appreciated and understood by students as much as those demonstrations performed live; in addition, students who watched demonstration videos often had better learning outcomes when compared to students who watched live demonstrations [48]. Supplementary videos may foster increased knowledge and performance in a laboratory setting by demonstrating how to perform an experiment, making potential pitfalls explicit and emphasizing the instructor's expectations. This may improve students' attitudes towards the physics laboratory [49].

In response to the growing demand for distance learning, several innovations in online physics laboratories have been developed. Reagan surveyed 398 institutions that offered introductory physics courses to assess the availability of fully online introductory physics courses and laboratories. They found that 38 institutions $(9.5 \%)$ offered at least one online physics course, and of those, 15 (3.8\%) offered a corresponding online laboratory course. The main reported objection as to why physics departments chose not to offer an online laboratory course was because they perceived a lack of hands-on engagement by students [50]. In addition to individual beliefs and knowledge, environmental factors such as time have also been reported as a significant factor that hinders the adaptation of new teaching strategies [51].

Online laboratories generally fall into four different varieties: (i) virtual laboratories, (ii) remote laboratories, (iii) video analysis of experiments, and (iv) hands-on experiments. While extensive research has been done in all of these variations (see Refs. [52-56] as examples), the focus of this review will be on hands-on experiments as they are the subject of the present study.

Hands-on labs conducted from a distance involve students using their own equipment, generally a "kit" purchased through a supplier that allows collection of "real time" data. To be practical, these hands-on labs must be affordable, transportable, safe, and require little or no supervision. They also provide the benefit of allowing experiments to be done at the student's own pace [11]. A potential downside to physics laboratories conducted this way is that the cost of lab equipment is transferred to students. While costs are typically comparable to the price of a textbook [11,50], not all students can afford such an expense.

Distance hands-on physics laboratories have been successfully implemented at a number of institutions [11,50,57-59]. Implementation of a purely online physics laboratory course utilizing the iOLab device, a tool with a wide range of sensors that collect and plot data, is less common and has been piloted at a few institutions [57,58]. Portland State University and Chemeketa Community College have run an online mechanics laboratory course for several years, adapting the RealTime Physics labs [60] with the iOLab device to serve their populations of distance learners. While the distance learners demonstrated higher normalized learning gains in Newtonian mechanics, there were no measurable differences in affective domains. The sample size was small, indicating a need for further research [57].

A potential disadvantage to any variation of online laboratories is that students generally work independently in setting up and conducting the experiment, as well as writing the lab report. Students taking in-person labs may seek help from their lab partners, classmates, faculty, a teaching assistant, or a laboratory technician immediately [11]. Further study is necessary to understand this isolation effect and how it may impact affective and cognitive domains.

\section{THEORETICAL FRAMEWORK}

\section{A. Epistemological views of physics learning}

The theoretical framework for this study was based upon research on students' epistemological views of physics learning, particularly in the social environment of the physics laboratory. Epistemological beliefs, or views of the nature of knowledge and learning, often influence how students choose academic behaviors in physics coursework $[14,61]$. Students' perceptions of physics learning may facilitate metacognition [27], or their ability to monitor their own learning to achieve specific goals [62].

Physics laboratory experiences often promote conceptual change through the integration of scientific knowledge with 


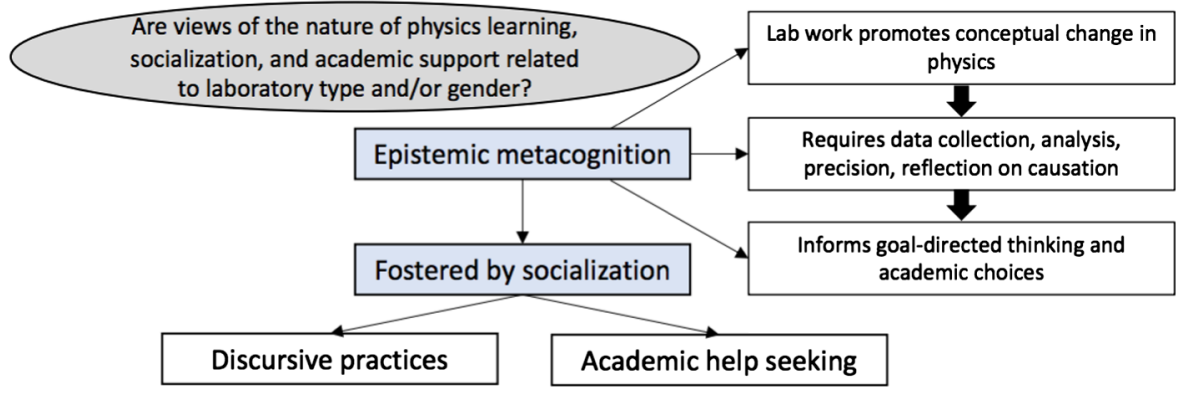

FIG. 1. Theoretical considerations for comparison of in-person and online learning environments.

students' prior experiences with the natural world [63]. Certain instructional practices in the laboratory may help this process, for example, requiring students to collect and analyze experimental results, establish precision, reconcile inconsistencies, identify causal elements, and answer reflective questions [27,28]. Epistemic discourse, which is often embedded in laboratory work, has often been instrumental in a groups'ability to articulate coherent conceptual claims [28].

\section{B. Social construction of knowledge}

The social basis for epistemological beliefs is echoed in Driver et al.'s work on the social processes involved in the construction of knowledge in science [64]. The authors proposed that scientific knowledge consists of ideas that allow students to interpret and explain physical phenomena, and such ideas are socially validated and communicated through discursive practices. Social interaction allows students to navigate through shifting cognitive schemes as they undergo conceptual change. These interactions might include the teachers' activities, interactions, and responses to student engagement in tasks, as well as the conversations among students as they interpret phenomena. In both cases, students' work in the physics laboratory may be viewed as a process in which they participate in the knowledge and skill acquisition associated with the scientific community. By sharing in conversations and argumentation in the context of scientific tasks, students are socialized in the epistemological facets of science learning [64]. The facilitation of close interconnected student networks has also been shown to be a predictor of future academic performance [65]. Student interactions may improve academic performance even when advice given has nothing to do with the course [66].

\section{Academic help seeking}

Metacognition fosters academic self-regulation, which enables students to know how and when to seek external help $[67,68]$. However, it is not enough for students to recognize they need help; they must choose to take proactive steps to seek the appropriate assistance to meet their learning and performance goals [69]. Academic help seeking has been viewed as social in nature since students must approach others [70]. Consequently, social barriers may preempt some learners from taking the necessary steps to reach out to peers and teachers for support, whether instruction takes place in person or in online learning environments [71-73].

Newman suggested that several resources are necessary for adaptive help seeking, or asking questions to master concepts (not simply finding the correct answers): (i) metacognitive competencies; (ii) social competencies; (iii) motivation and agency; and (iv) contextual motivational resources, such as collaborative activities [67]. When exploring potential differences between online and inperson laboratories, it is useful to examine students' preferences for help seeking, and how they report their help seeking behaviors in the absence of immediate access to teachers and peers. This may be important since help seeking in the asynchronous online learning environment has been shown to correlate with increased academic performance [74].

Figure 1 illustrates the theoretical basis for the comparison of in-person and online physics laboratory experiences in the context of students' views about epistemology, socialization, and academic help seeking.

\section{DESIGN}

The present study employed an observational, quasiexperimental, non-equivalent group design [75], exploring the experiences of students taking undergraduate physics labs in two course types-(1) in-person, collaborative, and (2) online, hands-on, individual. Students were enrolled in a calculus-based introductory physics course for first-year students. These course types were offered in the spring, summer, and fall sessions in 2019: (i) a classical course with large in-person lectures and standard, in-person physics labs where students worked in groups of two $(n=747)$; and (ii) an online course with labs done alone at home using the remote sensing device $(n=251)$.

\section{A. Context}

This survey was conducted at a large, public university in the northeastern United States. This university served 
nearly 18000 undergraduate students $(50.5 \%$ male and $49.5 \%$ female), of which $41.3 \%$ classified themselves as Asian, $9.5 \%$ as Black or African American, and $13.1 \%$ as Hispanic or Latino.

In person, collaborative labs enrolled approximately 900 students each semester, and the online, hands-on labs served roughly 325 students. These courses were part of a two-semester, calculus-based sequence. Enrolled students typically majored in the physical sciences, life sciences, or engineering. The laboratory was a required component of the introductory course, constituting $25 \%$ of the final grade.

\section{B. Course structures}

This study surveyed students enrolled in a physics laboratory and a calculus-based, introductory physics course, generally taken concurrently. The lecture course was either a large, traditional lecture with 500-700 students in a lecture hall or an online lecture course where students watched lecture videos online. Students primarily enrolled in the same laboratory course to match their lecture course (in-person or online), though some students chose to enroll in a different type.

Students in both course types had to complete ten laboratory experiments in topics covered in the corresponding lecture course, listed in Table I according to course type and semester. There was some variation in topics but both sets of experiments were designed for the students to meet similar learning objectives in terms of physics content knowledge and laboratory skill acquisition. Experiments in both settings generally followed prescribed laboratory procedures, although there was some opportunity for developing methodological approaches. In both course types, students were evaluated based on laboratory reports that were written individually. The final grade in the laboratory course was primarily based on these reports.

Each in-person laboratory section had approximately 24 students working in pairs in a special laboratory space. Students worked at laboratory tables in close proximity to one another with one instructor, typically a physics graduate student and teaching assistant, in the room. The teaching assistant would deliver a pre-laboratory lecture discussing the physics concepts involved in the investigation, as well as the equipment, procedure, and analytical techniques involved. Students used typical laboratory equipment that was set up for them before they arrived. Because the teaching assistant was in the room with the students, students had access to immediate help or feedback while conducting their experiments, in addition to conversing with their lab partners and other students in the room.

The online laboratories were generally conducted by students either in their dormitories on campus or in their homes off campus. Although there were online office hours with a teaching assistant or the professor, there was no
TABLE I. List of labs offered in the first and second semester of physics.

\begin{tabular}{ll}
\hline \hline In-person labs & \multicolumn{1}{c}{ Online labs } \\
\hline \multicolumn{1}{c}{ First semester-Mechanics } \\
\hline 1. Pendulum & 1. Linear Kinematics \\
2. Projectile Motion & 2. Force and Acceleration \\
3. Acceleration & 3. Force of Friction \\
4. Atwood Machine & 4. Circular Motion \\
5. Conservation of Energy & 5. Hooke's Law \& Springs \\
6. Conservation of Momentum & 6. Momentum \& Energy \\
7. Angular Momentum & 7. Simple Harmonic Motion \\
8. Standing Waves & 8. Simple Pendulum \\
9. Simple Harmonic Motion & 9. Standing Waves \\
10. Ideal Gas Law & 10. Speed of Sound \\
\hline
\end{tabular}

In-person labs Online labs

Second semester-Electricity and Magnetism

1. The Electric Field

2. The Oscilloscope

3. Capacitors

4. Ohm's Law

5. Magnetic Force

6. $\mathrm{e} / \mathrm{m}$ of the Electron

7. Inductors

8. Resonance

9. Geometric Optics

10. Interference

1. Electric Field Plotting

2. The Breadboard

3. Ohm's Law

4. Kirchhoff's Laws

5. RC Circuits

6. Magnetic Force

7. Magnetic Field

8. Faraday's Law

9. RLC Circuit

10. Snell's Law

11. Diffraction

formal discussion forum where students could converse with one another. Students purchased an iOLab device kit that included the device as well as other necessary equipment (springs, string, wires, laser pointer, etc.) to use for data collection. Students were required to use everyday items occasionally (headphones, cellphone, tape, paper, etc.). The iOLab is capable of connecting to a student's computer via a wireless USB dongle and utilizes software that comes with the device to record and plot data [76]. Students received instruction in graphical user interface (GUI) style software where information would be written on the left half of the screen regarding the theory, procedure, and analysis, as well as links to instructional videos and demonstrations on the laboratory procedures, how to calibrate the device, and data collection and analytical methods. Data were collected using this software and graphs were produced in real time, a technique that has been shown to improve physics learning [77,78]. If students had questions, they could contact one of six teaching assistants through email. Response time generally ranged from a few hours to several days.

To provide a tangible illustration of the similarities and differences between the traditional and online experiments, we describe the "Simple Harmonic Motion" laboratory. The in-person students worked with an air track with a cart 
attached to either end by springs. Students first determined the spring constant using the mass of the cart to stretch the spring a particular distance, then they measured the period of the cart oscillating back and forth across the track using a photogate. They increased the mass on the cart and measured the change in the period. Finally, students measured the velocity for the purpose of observing conservation of energy. Students graphed the tension as a function of displacement to determine the spring constant, and they plotted period squared as a function of mass to determine the spring constant from the slope of the line of best fit. Finally, they calculated the kinetic energy and potential energy of the system to determine whether the data were consistent with conservation of energy.

The online students attached a force sensor and a spring to their device and suspended it from a surface. They pulled the device down to allow it to oscillate. While oscillating, students measured the force experienced by the cart as a function of time. From the period of the wave, students calculated the frequency. They used the fast Fourier transform function in the software to calculate and identify the peak frequency, then compared it to the frequency found from the period. This was repeated for two more masses. The mass of the device could be increased by taping a cell phone or other household object onto it. Students graphed the frequency as a function of mass to determine the spring constant by fitting a non-linear function. An example of what the students observed during the data collection process is shown in Fig. 2.

\section{Survey administration}

To develop a means of evaluation for student differences in epistemological beliefs, and socialization and help seeking views, discussions were held with five physics faculty to discuss survey development. A preliminary survey was drafted after reviews of existing surveys and discussions with faculty to maximize construct validity. Select questions were taken from two surveys-the E-CLASS survey [79] and the Laboratory Classroom Environment Instrument for Senior High School Science [80]—however, additional questions were designed to collect data on affective constructs not addressed in the other surveys. Multiple survey revisions incorporated the results of these discussions with expert physics educators in the field. These iterations focused on item relevancy, clarity, and relationship to potential constructs deemed important in comparing laboratory learning environments [81]. For example, specific instructional expectations common to both laboratory types were incorporated in items that were designed to elicit epistemological beliefs about physics learning.

A pilot survey with 36 items was administered to a separate studio workshop class of life science majors, which had 56 responses. Based on the results as well as a thorough review of literature, questions were removed, added, and/or rephrased. After administration of a revised survey to the main sample, additional items were removed to maximize validity and construct reliability.

There were 24 questions in the final survey (Table II). A directed question was used to screen for inattentive

\section{Acquisition Sets}

Run1 (ID: 45ea18db-924c-43d1-bce0-ce2d5a299497) [Remove]

Force $(200 \mathrm{~Hz})$ Remote 1
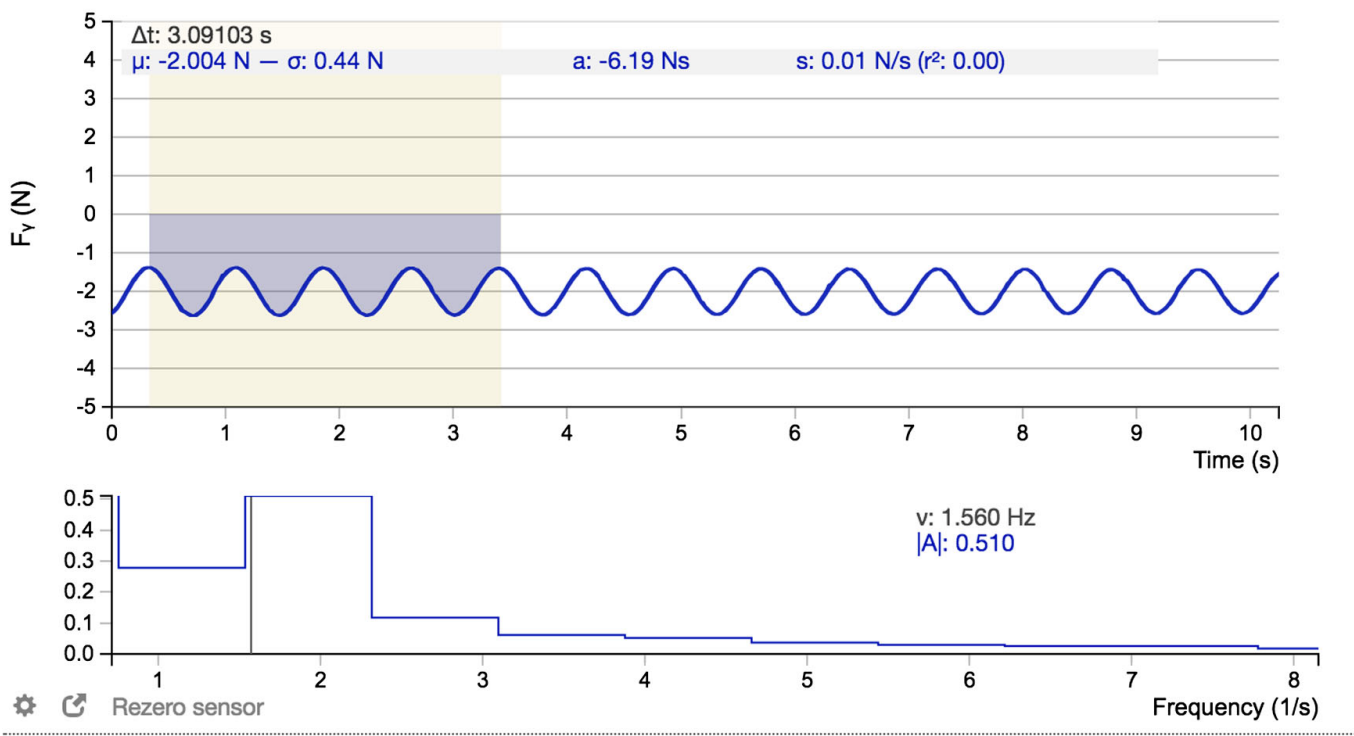

FIG. 2. Data collection sample for iOLab simple harmonic motion online laboratory. 
TABLE II. Survey of factors related to epistemological views, socialization, and help seeking in the physics laboratory.

FACTOR 1: Epistemological beliefs about physics laboratory work $(\alpha=0.86)$

1. I do not expect doing an experiment to help my understanding of physics.

2. I feel that I am learning physics while writing my lab report.

3. I feel that learning error analysis is an important part of my physics lab experience.

4. I feel the grading standards in the lab are unclear.

5. I feel that I am gaining laboratory skills that are useful outside of the physics course.

0.65

6. When doing an experiment, I try to understand how the experimental setup works.

7. When doing an experiment, I just follow the instructions without thinking about their purpose.

8. If I don't have clear directions for analyzing data, I am not sure how to choose

9. Physics knowledge from our regular physics lecture is integrated with laboratory activities.

10. The purpose behind a lab experiment is clear to me before I come to class.

11. Performing data analysis does not help me understand the physics concepts.

0.64

12. I better understand how to graph data because of the physics lab course.

0.52

13. I better understand how to do error analysis because of the physics lab course.

0.53

14. Before collecting data, I know what the results in an experiment are going to look like.

15. I do not enjoy doing lab experiments.

0.64

16. I am usually able to complete an experiment without understanding the related physics

17. When I approach a new piece of lab equipment, I feel confident I can learn how to use it well enough

for my purposes.

18. Calculating uncertainties usually helps me understand my results better.

FACTOR 2: Socialization in the laboratory $(\alpha=0.70)$

19. Having access to the teaching assistant (TA) while I am conducting an experiment is important to me.

20. I am more successful performing experiments with other people than if I had to do them on my own.

21. Working in a group is an important part of doing physics experiments.

FACTOR 3: Help seeking in the laboratory $(\alpha=0.71)$

22. I usually ask other students for help with technical issues (for example procedures, equipment)

respondents who did not read the questions to increase the statistical power of the survey [82]. Students' responses $(N=998)$ were rated on a five-point Likert scale ( $5=$ strongly agree, $4=$ agree, $3=$ neutral, $2=$ disagree, $1=$ strongly disagree). Some questions were reverse coded when calculating composites. Higher scores on composites indicated stronger agreement with positive epistemological beliefs, the value of socialization, and help seeking from instructors and peers. The survey had adequate overall reliability (Cronbach's $\alpha=0.81$ ). Sample sizes for individual constructs varied somewhat since missing responses were deleted listwise. There were 747 students in the traditional, in person lab setting and 251 students in the online lab setting who responded to this survey.

\section{RESULTS}

\section{A. Survey factor analysis}

To determine constructs of affective domains measured in the survey, an exploratory factor analysis with Varimax rotation was conducted with the finalized instrument. Since this was a newly developed instrument, exploratory factor analysis provided a preliminary assessment of the scale items, and latent constructs were determined based upon conceptual underpinnings and theoretical sensibility [83]. The sample size for factor analysis met the excellent-level criterion for a three-factor solution proposed by Mundfrom et al. [84]. In terms of model fit, the Kaiser-Meyer-Olkin measure of sampling adequacy was 0.86 , above the minimum threshold of 0.6 , and Bartlett's test of sphericity was significant $\left[\chi^{2}(276)=6366.54, p<0.001\right]$. The minimum primary factor loading threshold for inclusion was 0.40 , and no cross loadings exceeded 0.30 [85]. Each factor had at least three items, which is considered adequate representation [83,84,86,87]. Given these parameters, exploratory factor analysis was suitable for all 24 survey items.

Three constructs were identified: (i) epistemological beliefs about physics laboratory work; (ii) socialization in the laboratory; and (iii) help seeking in the laboratory. The post hoc descriptions of these constructs were determined and verified for content validity with the research 
team and a physics education expert. Acceptable interrater reliability was achieved after factored items were independently categorized in one round $(\kappa=0.81)$. The survey questions and primary factor loadings are indicated in Table II.

The first construct, "epistemological beliefs about physics laboratory work," was represented by 18 items $(\alpha=0.86)$. This construct included students' views of the purpose and benefits of performing physics experiments relating to their analytical skills, knowledge of physics concepts, confidence, instructional clarity, and enjoyment. Questions in Factor 1 asked about students' epistemological beliefs as they related to the laboratory course and how it facilitated their overall physics understandings. Questions were also related to how students thought or felt when doing the experiments and writing subsequent reports. Students were asked about skills they acquired and whether these skills were important to their success in their physics course and transferable to other science coursework. These included the processes involved with writing a lab report, calculating and analyzing experimental results, and error analysis. This factor also included the mechanical processes involved with performing an experiment.

The second construct, "socialization in the laboratory," was represented by three items $(\alpha=0.70)$. This construct included students' views of the value of interactions with peers and instructors in meeting the objectives of the laboratory course. Questions in factor 2 asked about students' perspectives of specific social dynamics. This included both peer to peer dynamics as well as how the students engaged with the teaching assistants. Also addressed was how socialization affected a student's success in the laboratory.

The third construct, "help seeking in the laboratory," was represented by three items $(\alpha=0.71)$. This construct measured students' perspectives of their comfort level with seeking assistance from others when experiencing uncertainty at any point during the experiment or subsequent analysis. Questions in Factor 3 asked about the processes that students undertook when they encountered problems. They related to hierarchical troubleshooting procedures starting from the individual, to a student's lab partner or fellow classmates, and finally to the teaching assistants. This factor addressed both technical questions that may have arisen over the course of a laboratory exercise as well as calculations and analysis.

\section{B. Analysis of constructs by laboratory type}

Comparisons of central tendency (independent-samples $t$ tests or Wilcoxon signed ranks) were conducted to determine whether there were differences between in-person and online laboratory students in terms of each of the three constructs identified. The mutually exclusive groups were compared in terms of composite scores generated from individual Likert items. The null hypothesis stated that there would be no differences between the groups in the three constructs identified in the factor analysis.

In terms of factor 1 (epistemological beliefs about physics laboratory work), online, hands-on students and in-person students demonstrated statistically similar perceptions $[t(974)=0.223, p=0.824]$.

For factor 2 (socialization in the laboratory), in-person students expressed significantly higher positive perceptions of the value of communication in the laboratory when compared to online, hands-on students. This difference was measured with a nonparametric Mann-Whitney test since the two groups did not exhibit homogeneity of variance in composite scores $(U=41032, p<0.001)$. This significant difference had a medium to large effect size $(r=0.42)$.

For factor 3 (help seeking in the laboratory), in-person students did not indicate significantly different perceptions of seeking assistance when compared to online, hands-on students. This difference was also measured with a MannWhitney test $(U=86170, p=0.117)$ due to nonequal variances in the samples. These results are summarized in Table III.

\section{Analysis of gender-based views by laboratory type}

The same three factors were explored with relation to student gender, with the null hypotheses assuming there would be no differences between groups with respect to each factor. Comparisons of means were generated.

When examining factor 1 , men showed significantly higher composites on their epistemological beliefs about physics laboratory work than women $[t(967)=3.333$, $p=0.001]$ with a small effect size (Cohen's $d=0.21$ ).

With regard to factor 2, socialization in the laboratory, there were no significant differences between men and women $[t(984)=0.870, p=0.385]$.

There was a significant difference in factor 3 (help seeking in the laboratory), with women reporting greater willingness to seek assistance from instructors and peers than men $[t(960)=2.101, p=0.036]$ with a weak effect size $(d=0.13)$. These results are also summarized in Table III.

\section{Interaction effects of laboratory type and gender}

The final analysis explored the presence of interaction effects when considering the joint effect of physics laboratory type and gender (Table IV). A two-way analysis of variance (ANOVA) was performed to measure interaction effects of course type and gender on the affective outcomes, as recommended by Field [88]. An interaction effect is the combined effect of two or more independent variables on a dependent variable, which in the present study may indicate: (i) the strength or direction of relationship between gender and affective outcomes is moderated by the second predictor (course type), or (ii) the strength or direction of relationship between course type and affective outcomes is moderated by the second predictor (gender). 
TABLE III. Statistical tests of subconstructs by laboratory course type and gender.

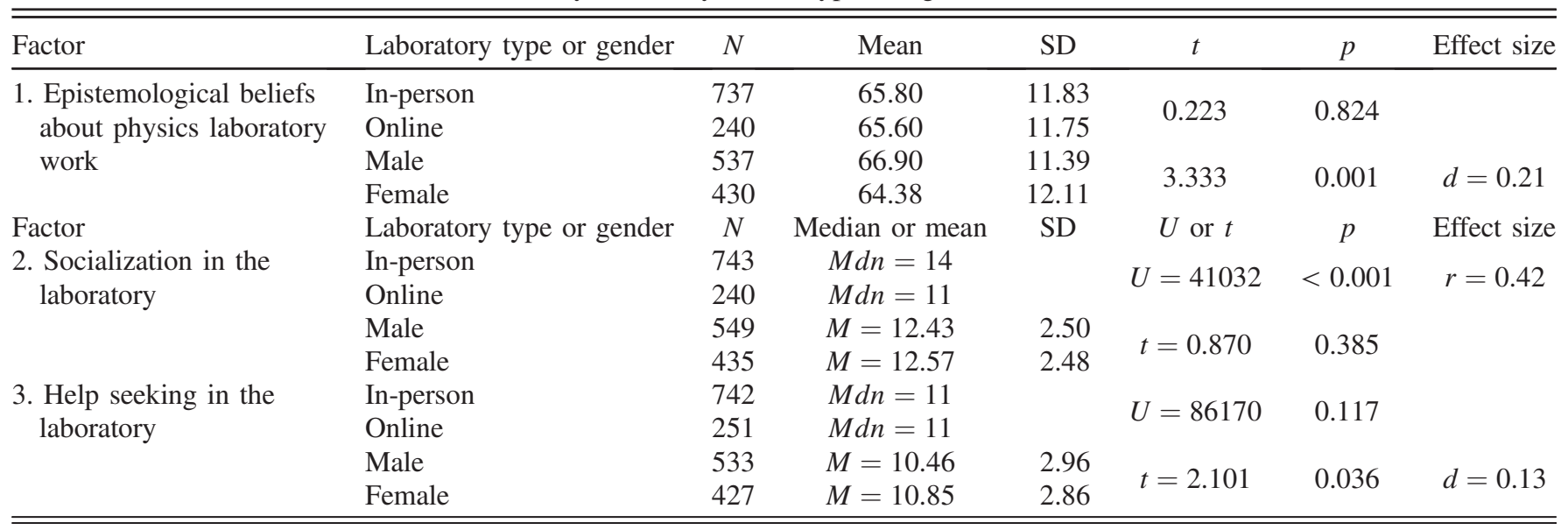

TABLE IV. Statistical tests of interaction effects of laboratory course type and gender.

\begin{tabular}{|c|c|c|c|c|c|c|c|}
\hline Factor & Laboratory type & Gender & $N$ & Mean & SD & $F$ & $p$ \\
\hline \multirow{4}{*}{ 1. Epistemological beliefs about physics laboratory work } & \multirow{2}{*}{ In-person } & Male & 400 & 67.10 & 11.77 & \multirow{4}{*}{0.381} & \multirow{4}{*}{0.537} \\
\hline & & Female & 327 & 68.31 & 12.07 & & \\
\hline & \multirow{2}{*}{ Online } & Male & 137 & 69.00 & 10.70 & & \\
\hline & & Female & 103 & 67.49 & 14.11 & & \\
\hline \multirow{4}{*}{ 2. Socialization in the laboratory } & \multirow{2}{*}{ In-person } & Male & 402 & 13.06 & 2.09 & \multirow{4}{*}{2.482} & \multirow{4}{*}{0.116} \\
\hline & & Female & 332 & 13.25 & 1.88 & & \\
\hline & \multirow{2}{*}{ Online } & Male & 147 & 10.68 & 2.71 & & \\
\hline & & Female & 103 & 10.35 & 2.88 & & \\
\hline \multirow{4}{*}{ 3. Help seeking in the laboratory } & \multirow{2}{*}{ In-person } & Male & 403 & 10.65 & 2.83 & \multirow{4}{*}{2.404} & \multirow{4}{*}{0.121} \\
\hline & & Female & 332 & 10.87 & 2.88 & & \\
\hline & \multirow{2}{*}{ Online } & Male & 147 & 9.91 & 3.24 & & \\
\hline & & Female & 104 & 10.80 & 3.38 & & \\
\hline
\end{tabular}

When the data were disaggregated by class type and gender, there were no interaction effects. That is, when comparing male and female students in each lab type, there were no significant differences in any of the three factors. Since the two-way ANOVA did not indicate significant interaction effects, it can be inferred that the combined effects of course type and gender did not moderate differences in affective outcomes. That is, men and women did not report different views of epistemology, socialization, and help seeking depending on the type of course in which they enrolled. Since gender-based views did not depend upon the type of course, the interpretations of the main separate effects were not moderated by other variables measured in the present study [89].

\section{DISCUSSION AND IMPLICATIONS}

\section{A. Students' views related to laboratory type}

With regard to the first two research questions, few affective differences between the in-person and online physics laboratories were noted, suggesting the promise of online, hands-on undergraduate laboratories in fostering similar epistemological beliefs and views of help seeking, while allowing for different student preferences with regard to socialization. Each of these results has important implications for undergraduate physics teaching and learning, particularly in light of logistical constraints related to recent systemic transitions to online learning in response to the global COVID-19 pandemic.

In terms of students' epistemological beliefs about laboratory work, students in both laboratory types expressed similar views about the objectives and benefits of performing physics experiments relating to their data collection and analytical skills, physics knowledge development, self-efficacy and enjoyment, and instructional clarity. Previous research has demonstrated a relationship between the way that labs are taught, not the environment in which they are taught, and the development of an epistemological stance [13]. Because students were taught in the same style, they shared the same epistemology independent 
of ease of access to other people. This research finding suggests that the epistemic elements embedded in laboratory instruction, intended to promote conceptual change while strengthening problem solving and data analysis, were viewed equally by students regardless of whether they performed experimental tasks in a collaborative laboratory setting or alone. This is notable since previous research has shown that students' views of physics learning fosters their metacognition and goal-directed thinking and actions [28]. Since differences in affective domains related to epistemology may influence retention, physics performance, and the ability of students to make connections between physics and other STEM disciplines [65], this finding implies that it is important for instructors of different types of laboratory courses to strive to promote equivalent epistemological beliefs.

The main difference between the in-person and online, hands-on laboratory courses was students' views of the value of socialization with peers and instructors. The students who enrolled in the in-person laboratories worked in groups of two with the teaching assistants in the room, whereas the online students did the experiments by themselves; the teaching assistants were available to answer questions via email. Students taking the in-person laboratory class placed a higher value the immediacy of the interactions with their laboratory partners, fellow classmates, and instructors (with a medium to large effect size). Although learning outcomes were not measured, these socialization beliefs were consistent with prior research on socially constructed science knowledge [64-66]. This finding implies that feedback from other students and the instructors was a factor in fostering their confidence in meeting laboratory objectives. Confidence in one's ability to meet these goals may have ramifications in terms of their success in future science and engineering courses, completing a degree, or pursuing a career in science and engineering $[17,18,90]$.

Conversely, students in the online laboratory did not value immediate socialization and feedback as much as their in-person peers. This implies that socialization may not be a necessary epistemological resource for all students, as suggested by prior research [64], however, this finding reflects students' beliefs about socialization and not whether it actually affected physics performance. One explanation for this finding may be that online students found their own resources to correct misconceptions or complete laboratory tasks, which did not necessarily involve discursive practices with peers and instructors. Because all communication with their teaching assistants was by email, there was a time delay between when a student encountered a problem and when the teaching assistant responded with a solution. Although this study did not examine whether the socialization missing from the online course hindered students' learning and performance in the laboratory course, the online students did not report socialization as an important factor in their laboratory experience.

The final set of results related to laboratory type explored students' views of help seeking in the physics laboratory, with no significant differences reported between in-person and online students. Students in both types of laboratories expressed a similar comfort level with seeking assistance from others when experiencing confusion during the experiment or subsequent analysis. It was unexpected that students in the online course would have similar views of help seeking, since no formal discussion groups were facilitated by the online course developers. This challenges prior claims regarding socially motivated help seeking [69], suggesting a broader definition of how help seeking is initiated, encouraged, and facilitated in online learning environments. This is consequential since adaptive help seeking has been shown to improve academic performance $[67,74]$.

\section{B. Students' views with regard to gender}

The third research question examined whether men and women had different views of epistemology, socialization, and help seeking, and whether these views were influenced by course type in terms of interaction effects. Although students taking the online, hands-on laboratory course reported equivalent epistemological beliefs about physics laboratory work when compared to their in-person counterparts, men overall valued laboratory tasks as part of their physics epistemology more so than women (with a small effect size). However, this difference was not significant when examining the interaction of laboratory type and gender; that is, there were no gender influences on epistemological beliefs when examining laboratory type individually. This suggests that allowing students to selfselect into their preferred laboratory learning structures may help diminish gender-based differences in beliefs about physics learning. If students are given the choice between in-person or online labs, they will likely choose the type that is consistent with their beliefs. Although men and women differed overall in epistemological beliefs, students with similar beliefs tended to choose the same type of laboratory course. Lessening the gender gap in epistemological beliefs is important since research has suggested these beliefs may impact academic performance [91].

Notably, there was no difference between women and men in terms of their views of socialization with peers and instructors in the laboratory, regardless of the type of laboratory course. This contradicts previous research that suggests women value socialization in science settings more so than their male peers [39-41]. Although this finding was not anticipated, it suggests that gender-based views of collaboration and teamwork were similar. As with epistemological beliefs, there was no interaction effect between gender and laboratory type in terms of views of socialization. Although students enrolled in in-person 
classes expressed a higher value of socialization, this finding was not influenced by gender. This implies that it may not be important to incorporate social interaction into laboratory coursework to facilitate task completion when considering differential gendered experiences and outcomes.

Although the final finding indicated that women placed a higher value on help seeking in the physics laboratory than men, the weak effect size suggests this statistical difference was negligible. Furthermore, there was no interaction effect between gender and laboratory type with regard to help seeking. This suggests that men and women had very similar beliefs regarding help seeking when experiencing uncertainty, regardless of whether they enrolled in online or in-person laboratory classes. This finding implies that social barriers previously associated with academic help seeking [70-73] may not exist with widespread use of social media, or these social barriers may not influence students' affective beliefs and learning experiences in the physics laboratory.

\section{LIMITATIONS}

There were several limitations in the research design and data analysis. Data were collected from students enrolled in physics courses at a single research university. Since all data were self-reported, survey responses may not reflect actual epistemological beliefs, views of socialization and help seeking. Self-reported beliefs may not correlate to physics performance, which was not measured in the present study. Variations in the pedagogical methods of the many laboratory instructors may have confounded the measured outcomes. The observational research design compared two types of laboratory courses in which students had self-selected; a randomized controlled study would allow exploration of student outcomes with minimized selection bias. Although this may be considered a limitation, in the case of the present study, self-selection was an important consideration in the analysis of students' perspectives.

Students in this study were only surveyed once after the first examination and the withdraw deadline giving sufficient time for students to become comfortable with the structure of each course and for their beliefs to form. While a predesign or postdesign could showcase changing beliefs over the course of a semester, it would not have been appropriate for this study. The experiential nature of some of the questions would prove difficult to answer by students in the first week of a laboratory course.

Inconsistencies in laboratory expectations and instruction between various sections may have influenced epistemological beliefs and attitudes towards help seeking. While physics learning was not measured in this study, students' epistemologies have been shown to be related to learning [91]. While physics laboratory work is often cited as a way to improve a student's performance in the physics course by reinforcing content, it is unclear whether such a benefit is consistently experienced by students $[92,93]$.

This study was based on one style, the canonical style, of laboratory, whereby students often confirmed existing physics theory through carefully prescribed procedures. Other laboratory teaching styles may provide a more explicit link between the construction of students' epistemologies and their value of socialization. Inquiry labs, for example, require a different classroom ecology including a social environment where students engage in argumentation and collaborative interpretation [94]. Such a style might foster a constructivist epistemology [13]. This study did not examine ways in which laboratory coursework might be structured to promote more inquiry-based learning.

\section{FUTURE RESEARCH}

The present study explored affective domains related to physics learning in various settings. More nuanced perspectives on students' attitudes may be elicited from qualitative data acquired through interviews, observations, and student artifacts. Given the rapid expansion of online alternatives for physics students, research may provide insights on the serendipitous student communication and social networks that arise from an online learning experience. Research in the field of distance learning must also keep up with advances in technology and the growing demands of online learners. Social interactions and construction of physics knowledge may assume different forms when considering the many electronic options for informal communications among students. Future research may also address academic factors such as physics comprehension, laboratory skill acquisition, and persistence in undergraduate science and engineering majors. Such studies might include large scale datasets to provide the necessary power for rigorous quantitative analysis. Future research should examine how online laboratory learning might complement in-person options while promoting physics learning among more diverse student populations.

\section{ACKNOWLEDGMENTS}

The authors would like to thank Thomas Hemmick, Laszlo Mihaly, Rich Lefferts, Ed Pascuzzi, Keith Sheppard, and the anonymous reviewers for their valuable insights. This research was supported by the State University of New York (SUNY) Excels Project and the Stony Brook University S-BOLD Initiative. The study was approved by the Stony Brook University Institutional Review Board (No. 1316679). 
[1] National Science Foundation, Shaping the Future: New Expectations for Undergraduate Education in Science, Mathematics, Engineering, and Technology (National Science Foundation, Washington, DC, 1996).

[2] National Academy of Sciences and National Academy of Engineering and Institute of Medicine, Rising Above the Gathering Storm: Energizing and Employing America for a Brighter Economic Future (The National Academies Press, Washington, DC, 2007).

[3] National Academy of Sciences and National Academy of Engineering and Institute of Medicine, Rising Above the Gathering Storm, Revisited: Rapidly Approaching Category 5 (The National Academies Press, Washington, DC, 2010).

[4] President's Council of Advisors on Science and Technology, Engage to Excel: Producing One Million Additional College Graduates with Degrees in Science, Technology, Engineering, and Mathematics (Executive Office of the President, Washington, DC, 2012).

[5] National Research Council, Adapting to a Changing World: Challenges and Opportunities in Undergraduate Physics Education (National Academies Press, Washington, DC, 2013).

[6] American Physical Society, Phys21: Preparing Physics Students for 21st-Century Careers: A Report by the Joint Task Force on Undergraduate Physics Programs (American Physcial Society, College Park, MD, 2016).

[7] J. Kozminski, H. J. Lewandowski, N. Beverly, S. Lindaas, D. Deardorff, A. Reagan, R. Dietz, R. Tagg, M. EblenZayas, J. Williams, R. Hobbs, and B. M. Zwickl, AAPT committee on laboratories, in AAPT Recommendations for the Undergraduate Physics Laboratory Curriculum (AAPT, College Park, MD, USA, 2014).

[8] Achieve, Inc., Next Generation Science Standards: For States, By States (The National Academies Press, Washington, DC, 2013).

[9] A. Karelina and E. Etkina, Acting like a physicist: Student approach study to experimental design, Phys. Rev. Phys. Educ. Res. 3, 020106 (2007).

[10] R. T. White, The link between the laboratory, learning, Int. J. Sci. Educ. 18, 761 (1996).

[11] F. Al-Shamali and M. Connors, Low-cost physics home laboratory, in Accessible Elements: Teaching Science Online and at a Distance, edited by D. K. Kennepohl and L. Shaw (Athabasca University Press, Edmonton, AB, 2010) p. 131.

[12] E. F. Redish, J. M. Saul, and R. N. Steinberg, Student expectations in introductory physics, Am. J. Phys. 66, 212 (1998).

[13] W.-M. Roth and A. Roychoudhury, Physics students' epistemologies and views about knowing and learning, J. Res. Sci. Teach. 31, 5 (1994).

[14] D. Hammer, Epistemological beliefs in introductory physics, Cognit. Instr. 12, 151 (1994).

[15] B. Ost, The role of peers and grades in determining major persistence in the sciences, Econ. Educ. Rev. 29, 923 (2010).

[16] A. Zohar and B. Bronshtein, Physics teachers' knowledge and beliefs regarding girls' low participation rates in advanced physics classes, Int. J. Sci. Educ. 27, 61 (2005).
[17] E. Seymour and N. M. Hewitt, Talking About Leaving: Why Undergraduates Leave the Sciences (Westview Press, Boulder, CO, 1997).

[18] V. Tinto, Research and practice of student retention: What next?, J. Coll. Stud. Retention: Res. Theory Pract. 8, 1 (2006).

[19] G. Nehmeh and A. M. Kelly, Self-determination of undergraduate women in physics: The role of external validation, Res. Sci. Technol. Educ. (2020), https://doi.org/10.1080/ 02635143.2020 .1740668$.

[20] A. Hofstein and V. N. Lunetta, The laboratory in science education: Foundations for the twenty-first century, Sci. Educ. 88, 28 (2004).

[21] National Science Teachers Association, Position Statement: The Integral Role of Laboratory Investigations in Science Instruction (NSTA, Arlington, VA, 2007), https:// www.nsta.org/nstas-official-positions/integral-rolelaboratory-investigations-science-instruction.

[22] A.E. Moyer, Edwin hall and the emergence of the laboratory in teaching physics, Phys. Teach. 14, 96 (1976).

[23] R. Trumper, The physics laboratory-a historical overview and future perspectives, Sci. Educ. 12, 645 (2003).

[24] M. P. Clough, Using the laboratory to enhance student learning, in Learning Science and the Science of Learning, edited by R. W. Bybee (National Science Teachers Association, Arlington, VA, 2002), pp. 85-94.

[25] R. Driver, P. Newton, and J. Osborne, Establishing the norms of scientific argumentation in classrooms, Sci. Educ. 84, 287 (2000).

[26] G. Richmond and J. Striley, Making meaning in classrooms: Social processes in small-group discourse and scientific knowledge building, J. Res. Sci. Teach. 33, 839 (1996).

[27] D. Hammer and A. Elby, Tapping epistemological resources for learning physics, J. Learn. Sci. 12, 53 (2003).

[28] W. A. Sandoval, Conceptual and epistemic aspects of students' scientific explanations, J. Learn. Sci. 12, 5 (2003).

[29] A.-M. Hoskinson, B. A. Couch, B. M. Zwickl, K. A. Hinko, and M. D. Caballero, Bridging physics and biology teaching through modeling, Am. J. Phys. 82, 434 (2014).

[30] B. D. Geller, C. Turpen, and C. H. Crouch, Sources of student engagement in introductory physics for life sciences, Phys. Rev. Phys. Educ. Res. 14, 010118 (2018).

[31] D. W. Johnson, R. T. Johnson, and K. A. Smith, Cooperative learning: Improving university instruction by basing practice on validated theory, J. Excellence Coll. Sci. Teach. 25, 1 (2014), http://celt.muohio.edu/ject/issue .php? $\mathrm{v}=25 \& \mathrm{n}=3 \% 20$ and $\% 204$.

[32] E. Kyndt, E. Raes, B. Lismont, F. Timmers, E. Cascallar, and F. Dochy, A meta-analysis of the effects of face-to-face cooperative learning. do recent studies falsify or verify earlier findings?, Educ. Res. Rev. 10, 133 (2013).

[33] B. Latour and S. Woolgar, Laboratory Life: The Construction of Scientific Facts (Princeton University Press, Princeton, NJ, 2013).

[34] C. A. Chinn and B. A. Malhotra, Epistemologically authentic inquiry in schools: A theoretical framework for evaluating inquiry tasks, Sci. Educ. 86, 175 (2002). 
[35] K. Tobin, Research on science laboratory activities: In pursuit of better questions and answers to improve learning, School Sci. Math. 90, 403 (1990).

[36] K. L. Van De Bogart, D. R. Dounas-Frazer, H. Lewandowski, and M. R. Stetzer, Investigating the role of socially mediated metacognition during collaborative troubleshooting of electric circuits, Phys. Rev. Phys. Educ. Res. 13, 020116 (2017).

[37] B. Kehrwald, Understanding social presence in text-based online learning environments, Distance Educ. 29, 89 (2008).

[38] J. C. Blickenstaff, Women and science careers: leaky pipeline or gender filter?, Gender Educ. 17, 369 (2005).

[39] A. M. Kelly, Social cognitive perspective of gender disparities in undergraduate physics, Phys. Rev. Phys. Educ. Res. 12, 020116 (2016).

[40] E. Alexopoulou and R. Driver, Gender differences in small group discussion in physics, Int. J. Sci. Educ. 19, 393 (1997).

[41] P. Labudde, W. Herzog, M. P. Neuenschwander, E. Violi, and C. Gerber, Girls and physics: Teaching and learning strategies tested by classroom interventions in grade 11 , Int. J. Sci. Educ. 22, 143 (2000).

[42] U.S. Department of Education, Digest of Education Statistics (Institute of Education Sciences, National Center for Education Statistics, Washington, DC, 2018).

[43] J. E. Seaman, I. E. Allen, and J. Seaman, Grade Increase: Tracking Distance Education in the United States (Babson Survey Research Group, Babson Park, MA, 2018).

[44] B. A. Sherwood and R. W. Chabay, Integrating theory and experiment in lecture using desktop experiments, AIP Conf. Proc. 399, 1053 (1997).

[45] C. Colwell, E. Scanlon, and M. Cooper, Using remote laboratories to extend access to science and engineering, Comput. Educ. 38, 65 (2002).

[46] S. Burgstahler, B. Corrigan, and J. McCarter, Making distance learning courses accessible to students and instructors with disabilities: A case study, Internet Higher Educ. 7, 233 (2004).

[47] D. Magin and S. Kanapathipillai, Engineering students' understanding of the role of experimentation, Eur. J. Eng. Educ. 25, 351 (2000).

[48] G. Kestin, K. Miller, L. S. McCarty, K. Callaghan, and L. Deslauriers, Comparing the effectiveness of online versus live lecture demonstrations, Phys. Rev. Phys. Educ. Res. 16, 013101 (2020).

[49] L.S. Nadelson, J. Scaggs, C. Sheffield, and O.M. McDougal, Integration of video-based demonstrations to prepare students for the organic chemistry laboratory, J. Sci. Educ. Technol. 24, 476 (2015).

[50] A. M. Reagan, Development of a fully online undergraduate physics laboratory course, in Proceedings of the American Association of Physics Teachers 2011 Winter Meeting, Jacksonville, FL, USA (American Association of Physics Teachers, College Park, MD, 2011).

[51] M. Dancy and C. Henderson, Pedagogical practices and instructional change of physics faculty, Am. J. Phys. 78, 1056 (2010).

[52] J. J. Chini, A. Madsen, E. Gire, N. S. Rebello, and S. Puntambekar, Exploration of factors that affect the com- parative effectiveness of physical and virtual manipulatives in an undergraduate laboratory, Phys. Rev. Phys. Educ. Res. 8, 010113 (2012).

[53] Z. Merchant, E. T. Goetz, L. Cifuentes, W. KeeneyKennicutt, and T. J. Davis, Effectiveness of virtual realitybased instruction on students' learning outcomes in k-12 and higher education: A meta-analysis, Comput. Educ. 70, 29 (2014).

[54] J. Ma and J. V. Nickerson, Hands-on, simulated, and remote laboratories: A comparative literature review, ACM Comput. Surv. 38, 7 (2006).

[55] L. Gomes and S. Bogosyan, Current trends in remote laboratories, IEEE Transactions on Industrial Electronics 56, 4744 (2009).

[56] D. Brown and A. J. Cox, Innovative uses of video analysis, Phys. Teach. 47, 145 (2009).

[57] E. Bodegom, E. Jensen, and D. Sokoloff, Adapting realtime physics for distance learning with the iolab, Phys. Teach. 57, 382 (2019).

[58] T. Sato and J. Lang, Poster: An online lab section with iolab and remotely operated experiments, in American Association of Physics Teachers Physics Education 2017 Summer Meeting, Cincinnati, Ohio, USA. (American Association of Physics Teachers, College Park, MD, 2017).

[59] J. Turner and A. Parisi, Take-home physics experiment kit for on-campus and off-campus students, Teach. Sci. 54, 20 (2008), https://eprints.usq.edu.au/4377/.

[60] D. R. Sokoloff, R. K. Thornton, and P. W. Laws, RealTime Physics: Active Learning Laboratories, Module 1: Mechanics (John Wiley \& Sons, Hoboken, NJ, 2011).

[61] A. Elby, Helping physics students learn how to learn, Am. J. Phys. 69, S54 (2001).

[62] D. J. Hacker, J. Dunlosky, and A. C. Graesser, Metacognition in educational theory and practice (Routledge, New York, NY, 1998).

[63] W. Kyle and J. A. Shymansky, Enhancing learning through conceptual change teaching, Research Matters - To the Science Teacher 8902 (1989), https://narst.org/researchmatters/enhancing-learning-through-conceptual-changeteaching.

[64] R. Driver, H. Asoko, J. Leach, P. Scott, and E. Mortimer, Constructing scientific knowledge in the classroom, Educ. Res. 23, 5 (1994).

[65] E. A. Williams, J. P. Zwolak, R. Dou, and E. Brewe, Linking engagement and performance: The social network analysis perspective, Phys. Rev. Phys. Educ. Res. 15, 020150 (2019).

[66] R. A. Smith and B. L. Peterson, "psst... what do you think?" the relationship between advice prestige, type of advice, and academic performance, Commun. Educ. 56, 278 (2007).

[67] R.S. Newman, How self-regulated learners cope with academic difficulty: The role of adaptive help seeking, Theory Pract. 41, 132 (2002).

[68] P. R. Pintrich, An achievement goal theory perspective on issues in motivation terminology, theory, and research, Contemp. Educ. Psychol. 25, 92 (2000).

[69] A. M. Ryan and P. R. Pintrich, Achievement and social motivational influences on help seeking in the classroom, in Strategic Help Seeking: Implications for Learning and 
Teaching, edited by S. A. Karabenick (Lawrence Erlbaum Associates Publishers, Mahwah, NJ, 1998), pp. 117-139.

[70] S. A. Karabenick and R. S. Newman, Seeking help: Generalizable self-regulatory process and social-cultural barometer, in Contemporary Motivation Research: From Global to Local Perspectives, edited by M. Wosnitza, S. A. Karabenick, E. Anastasia, and P. Nenniger (Hogrefe \& Huber Publishers, Cambridge, MA, 2009), pp. 25-48.

[71] K. E. Dunn, G. C. Rakes, and T. A. Rakes, Influence of academic self-regulation, critical thinking, and age on online graduate students' academic help seeking, Distance Educ. 35, 75 (2014).

[72] K. Mäkitalo-Siegl and F. Fischer, Stretching the limits in help-seeking research: Theoretical, methodological, and technological advances, Learn. Instr. 21, 243 (2011).

[73] A. M. Ryan and H. Shin, Help-seeking tendencies during early adolescence: An examination of motivational correlates and consequences for achievement, Learn. Instr. 21, 247 (2011).

[74] I. Roll, V. Aleven, B. M. McLaren, and K. R. Koedinger, Improving students' help-seeking skills using metacognitive feedback in an intelligent tutoring system, Learn. Instr. 21, 267 (2011).

[75] C.S. Reichardt, Quasi-experimental design, in The SAGE Handbook of Quantitative Methods in Psychology, edited by R. E. Millsap and A. Maydeu-Olivares (Sage, London, UK, 2009), Vol. 46, pp. 490-500.

[76] iOLab Macmillan Learning, http://www.iolab.science/ documents/iOLab_Description_onepage.pdf. Accessed 12-31-2019.

[77] R. K. Thornton and D. R. Sokoloff, Learning motion concepts using real-time microcomputer-based laboratory tools, Am. J. Phys. 58, 858 (1990).

[78] H. Brasell, The effect of real-time laboratory graphing on learning graphic representations of distance and velocity, J. Res. Sci. Teach. 24, 385 (1987).

[79] B. M. Zwickl, T. Hirokawa, N. Finkelstein, and H. J. Lewandowski, Epistemology and expectations survey about experimental physics: Development and initial results, Phys. Rev. Phys. Educ. Res. 10, 010120 (2014).

[80] B. J. Fraser, C. J. McRobbie, and G. J. Giddings, Development and cross-national validation of a laboratory classroom environment instrument for senior high school science, Sci. Educ. 77, 1 (1993).

[81] American Educational Research Association and American Psychological Association and National Council on Meas- urement in Education and Joint Committee on Standards for Educational and Psychological Testing (US), Standards for Educational and Psychological Testing (American Educational Research Association, Washington, DC, 2014).

[82] M. R. Maniaci and R. D. Rogge, Caring about carelessness: Participant inattention and its effects on research, J. Res. Pers. 48, 61 (2014).

[83] L. R. Fabrigar, D. T. Wegener, R. C. MacCallum, and E. J. Strahan, Evaluating the use of exploratory factor analysis in psychological research, Psychol. Methods 4, 272 (1999).

[84] D. J. Mundfrom, D. G. Shaw, and T. L. Ke, Minimum sample size recommendations for conducting factor analyses, Int. J. Nondestr. Test. 5, 159 (2005).

[85] J. P. Stevens, Applied Multivariate Statistics for the Social Sciences (Routledge, Mahwah, NJ, 2012).

[86] R. C. MacCallum, K. F. Widaman, S. Zhang, and S. Hong, Sample size in factor analysis, Psychol. Methods 4, 84 (1999).

[87] L. R. Tucker, R. F. Koopman, and R. L. Linn, Evaluation of factor analytic research procedures by means of simulated correlation matrices, Psychometrika 34, 421 (1969).

[88] A. Field, Discovering Statistics Using IBM SPSS Statistics (Sage, Los Angeles, CA, 2013).

[89] B. Winer, D. Brown, and K. Michels, Statistical Principles in Experiment Design (McGraw-Hill, New York, NY, 1991).

[90] G. Hardy, Academic self-concept: Modeling and measuring for science, Res. Sci. Educ. 44, 549 (2014).

[91] L. Lising and A. Elby, The impact of epistemology on learning: A case study from introductory physics, Am. J. Phys. 73, 372 (2005).

[92] N. Holmes, J. Olsen, J. L. Thomas, and C. E. Wieman, Value added or misattributed? A multi-institution study on the educational benefit of labs for reinforcing physics content, Phys. Rev. Phys. Educ. Res. 13, 010129 (2017).

[93] C. Wieman and N. Holmes, Measuring the impact of an instructional laboratory on the learning of introductory physics, Am. J. Phys. 83, 972 (2015).

[94] E. Etkina, A. Karelina, M. Ruibal-Villasenor, D. Rosengrant, R. Jordan, and C. E. Hmelo-Silver, Design and reflection help students develop scientific abilities: Learning in introductory physics laboratories, J. Learn. Sci. 19, 54 (2010). 